\title{
Stress, Organizational Citizenship Behaviors, and Coping: Comparisons among Plateaued and Non-Plateaued Employees
}

Carrie S. Hurst (Corresponding author)

Tennessee State University

Department of Business Administration

330 10th Avenue North, Nashville, TN, USA 37203

Tel: 615-963-7341Ｆax: 615-963-7139Ｅ-mail: churst@tnstate.edu

\section{Kenneth Kungu}

Tennessee State University

Department of Business Administration

330 10th Avenue North, Nashville, TN, USA 37203

Tel: 615-963-7371 Fax: 615-963-7139 E-mail: kkungu@tnstate.edu

Phyllis Flott

Tennessee State University

Department of Business Administration

330 10th Avenue North, Nashville, TN, USA 37203

Tel: 615-963-7135Ｆax: 615-963-7139Ｅ-mail: pflott@tnstate.edu

Received: July 4, 2012

doi:10.5430/bmr.v1n3p17
Accepted: July 18, 2012

Online Published: July 26, 2012

\begin{abstract}
Hierarchical plateaus occur when employees lack upward mobility, and job content plateaus occur when employees lack challenge or responsibilities in their roles. Results of this study extend research on the outcomes of plateaus by considering stress and organizational citizenship behaviors (OCBs). Plateaus were positively related to stress and negatively related to OCBs. We also examined differences in coping strategies by incorporating responses from non-plateaued as well as three groups of plateaued employees. Non-plateaued employees reported higher usage of non-work coping strategies compared to double plateaued employees, and those reporting no hierarchical plateau reported greater use of non-work coping strategies than hierarchically plateaued employees. These results provide some initial insights on how non-plateaued employees might be successfully avoiding plateaus in their careers. Lastly, job involvement and non-work coping strategies were negatively related to stress. Implications of these results for research and practice are also discussed.
\end{abstract}

Keywords: Hierarchical plateau, Job content plateau, Double plateau, Stress, Organizational citizenship behaviors, Coping

\section{Introduction}

The U.S. unemployment rate in May 2012 was 8.2\% (Bureau of Labor Statistics, 2011). It remains unclear when the labor market will improve in any substantial way, leaving many employees who have lost their jobs still searching for employment. In addition to the unemployed, many individuals are also under-employed. For example, the number of marginally attached workers is has also risen and indicates those who have searched for a job over the past year but not in the preceding 4 weeks (Bureau of Labor Statistics, 2011). Another indicator of under-employment involves plateaued individuals lacking growth or advancement in their careers, which may also be on the rise as a result of the current economic climate. 
Plateaus can occur when individuals perceive either a low likelihood of promotion within their careers (hierarchical plateau), low levels of challenge or responsibility (job content plateau), or both (double plateau) (Allen, Russell, Poteet, \& Dobbins, 1999; McCleese, Eby, Scharlau, \& Hoffman, 2007). Plateaus have been linked to a wide range of negative individual and organizational consequences, including lower work attitudes and job performance and higher absenteeism and turnover (Allen, Poteet, \& Russell, 1998; Chao, 1990; Ettington, 1998; Heilmann, Holt, \& Rilovick, 2008; Klehe, Zikic, Van Vianen, \& De Pater, 2011; Lee, 2003; Lemire, Saba, \& Gagnon, 1999; Near, 1985). However, despite the many negative consequences associated with plateaus, contradictory findings exist regarding stress as an outcome of plateauing (Allen, et al., 1998; McCleese et al., 2007). Surprisingly, organizational citizenship behaviors (OCBs) have not been examined in relation to a hierarchical plateau, though social exchange theory (Blau, 1964) suggests plateaued employees may be less likely to engage in such behaviors in order to reciprocate for a perceived injustice from their failure to advance or receive developmental opportunities. Understanding how plateaus influence these important behaviors is important for revealing the full range of consequences associated with plateauing. Likewise, although researchers have begun examining coping strategies of plateaued employees (Hurst \& Kungu, 2011; McCleese, et al., 2007; Rotondo \& Perrewe, 2000), an examination of these coping strategies among non-plateaued employees compared to those experiencing some type of plateau has yet to be empirically tested. The existing research on coping with plateaus assumes certain coping strategies may be more prevalent depending on the type of plateau experienced (Hurst \& Kungu, 2011; McCleese et al., 2007). However, it is also important to consider the coping strategies reported by non-plateaued employees, as this may provide some insight into which activities may be important for avoiding a plateau in one's career. The current focus on only plateaued employees' coping strategies represents an important gap in the literature that should be addressed.

The purpose of this study is twofold: First, we intend to extend the range of outcomes linked to plateauing by examining stress and OCBs among hierarchically and job content plateaued employees. Second, we examine comparisons of reported copings strategies among non-plateaued, hierarchically plateaued, job content plateaued, and double plateaued employees. Lastly, although the relationship between general coping and stress is well-established, we examine this relationship using McCleese et al.'s (2007) taxonomy of plateau coping strategies. Establishing this link is important for researchers and practitioners interested in encouraging adaptive coping strategies for plateaued employees.

\subsection{Existing Research on Plateaus}

The majority of plateauing research focuses on hierarchical plateaus, which occur when individuals have low perceptions of upward mobility opportunities in the organization (Ference, et al., 1977). However, some researchers (Chao, 1990; Choy and Savery 1998) argue this focus on hierarchical plateaus provides a limited perspective on individuals' career mobility. Therefore, more recent research also recognizes job content plateaus, characterized by boredom and lack of challenge in one's job (Allen, et al., 1998; McCleese, et al., 2007) as well as double plateaus, occurring when individuals simultaneously experience a hierarchical and job content plateau (Allen, et al., 1998, 1999; McCleese et al., 2007).

The existing research has focused on both antecedents and outcomes of being plateaued. For example, hierarchical plateaus may be more frequently reported among older and more tenured workers (Hurst \& Eby, 2010; Tremblay \& Roger, 1993), whereas job content plateaus have been linked to lower levels of education (Allen, Poteet, \& Russell, 1998; Hurst \& Eby, 2010). In addition, plateaus are associated with a wide variety of negative work-related consequences for individuals and organizations. For employees, plateaus have been linked to poorer attitudes such as lower job satisfaction, organizational commitment, and career satisfaction (Allen et al., 1998; Chao, 1990; Lee, 2003; McCleese \& Eby, 2006). Negative consequences for the organization include increased absenteeism and turnover and lower performance (Allen et al., 1998; Ettington, 1999; Heilmann et al., 2008; Klehe et al., 2011; Near, 1985; Saba, et al., 1999).

\subsection{Stress and OCBs among Plateaued Employees}

Allen and colleagues (1998) found that hierarchical plateaus were linked to higher stress among employees but job content plateaus were not, whereas McCleese, et al. (2007) found that both types of plateaus were reported as stressful. Hurst and Eby (2010) argue that individuals' experiences of stress as a result of plateauing may depend on their appraisals of the situation. Cognitive appraisal is a process individuals use to determine why and to what extent a particular situation is significant for one's well-being (Lazarus \& Folkman, 1984). Primary appraisal is used to determine what is at stake for the individual in a potentially stressful situation, whereas secondary appraisal is used to evaluate the appropriateness of existing responses. Hurst and Eby found that neither hierarchically plateaued nor job content plateaued employees associated high stakes with their situations (primary appraisal) or felt as if there was little 
they could do to change the situations (secondary appraisal). However, they also noted that individuals might have initially perceived the situations as stressful and later re-evaluated their plateaus after having coped in some way. Considering these conflicting findings in terms of whether plateaus are stressful experiences, and because understanding stress is important for conceptualizations of coping (Lazarus \& Folkman, 1984), we propose the following hypothesis to re-examine this issue:

Hypothesis 1: Plateaus will be positively related to stress.

Plateaus may also negatively affect employees by influencing their engagement in OCBs. Individuals who engage in OCBs go above and beyond the formal requirements of their jobs to help the organization (Podsakoff, MacKenzie, Paine, and Bachrach, 2000). OCBs have not been examined to date in relation to plateauing but the negative relationships observed between plateaus and job performance (Allen, et al., 1998; Ettington, 1998; Lemire et al., 1999) indicates employees may reduce their job performance when they feel stifled in their careers. It seems plausible that if plateaued employees are willing to reduce effort for their mandatory tasks at work, they may also be less willing to engage in extra-role behaviors such as OCBs. Career advancement is an important source of motivation (Chay, Aryee, \& Chew, 1995; Tremblay, Roger, \& Toulouse, 1995) and plateaued employees may not be motivated to exert any extra effort if they do not believe it will be recognized or rewarded. Further, social exchange theory (Blau, 1964), suggests individuals who perceive high-quality relationships with their employers may feel obligated to reciprocate in positive ways. In contrast, if being plateaued is an undesirable career situation and individuals hold their employing organizations at least partly responsible for their career advancement status, they might withhold OCBs as a way to retaliate for some perceived injustice. Based on this logic and rationale, the following hypothesis is proposed:

Hypothesis 2: Plateaus will be negatively related to organizational citizenship behaviors.

\subsection{Coping with Plateaus}

Some research has begun to examine coping strategies employees use to deal with the experience of being plateaued. Rotondo and Perrewe (2000) examined a number of "positive" (e.g., project or team involvement) and "negative denial" coping strategies (e.g., blaming one's supervisor or organization) among hierarchically plateaued employees. McCleese et al. (2007) examined coping by asking employees open-ended questions about their coping strategies and proposed a taxonomy of seven major coping strategies plateaued employees reported using to deal with job content and hierarchical plateaus. These included discussing the problem, job involvement, non-work activities, mental coping, and side work, with some employees reporting doing "nothing" to cope. Results revealed differences in the reported frequency of certain coping strategies based on the type of plateau experienced only for mental coping strategies (e.g., controlling emotions, accepting or ignoring the plateau), with hierarchically plateaued employees reporting greater use of mental coping strategies than job content or double plateaued. However, McCleese and colleagues only reported differences in coping if the difference in the observed frequency was greater than $5 \%$. Further, this research relied on a relatively small sample. Lentz and Allen's (2009) study also provided some empirical support for the idea that the effectiveness of coping may depend on the type of plateau experienced, with results revealing that mentoring (a "non-work activity" in McCleese et al.'s taxonomy) may help in coping with a job content plateau but not a hierarchical plateau.

Examining differences in coping strategies based on the type of plateau experienced is important for understanding the activities in which plateaued employees are engaging to manage their unique career experiences. However, considering experiences of those employees who are not plateaued might also shed light on the effectiveness of coping strategies. In other words, these employees may hold the key to understanding what might be done to avoid plateaus (Hurst \& Kungu, 2011). Plateauing research has considered the experiences of non-plateaued employees in order to draw comparisons on predictors of plateauing. While this has helped highlight certain demographic characteristics, such as age, gender, and tenure, that may be helpful for avoiding plateaus (Allen et al., 1998; 1999), we are aware of no research to date that considers the coping strategies of non-plateaued employees. Therefore, we pose the following exploratory research question:

Research Question 1: Do plateaued and non-plateaued employees differ in their use of coping strategies?

Effective coping should eliminate or reduce the negative consequences associated with plateauing (Hurst \& Kungu, 2011). Folkman and Lazarus (1980) defined coping as the thoughts and actions individuals use to manage stressful events. A wide range of options are available for individuals to improve coping with work stress and quality of work life (Carvalho \& Cunha, 2009), and although it is generally well-accepted that coping should reduce stress, many of the specific coping strategies outlined in McCleese and colleagues' (2007) taxonomy have not been examined in relation to stress. As the authors note, some of the plateau coping strategies identified by the plateaued participants (e.g., 
discuss problem, mental coping) may be similar to items on existing coping inventories, whereas other more career-specific forms of coping are not (e.g., job withdrawal, job involvement).

Establishing the relationships between these categories of coping and stress is important in order to shed light on which coping strategies may be most effective for managing plateaus. Job withdrawal includes coping behaviors such as reducing the number of hours worked and avoiding more responsibility (McCleese, et al., 2007). For some plateaued employees, job withdrawal may be the only viable alternative left for dealing with their plateaus. That is, if an employee fails to advance or perceive challenge in their position over an extended period of time, he or she might cease exerting extra effort or seeking additional responsibilities to reduce the stress experienced from being plateaued. Job involvement includes activities such as training, lateral moves, and increasing job knowledge (McCleese, et al., 2007). This category of coping is consistent with problem-focused coping in that it might be aimed at directly reducing the stressor, itself, rather than emotion-focused forms of coping that reduce the negative emotions resulting from the stressor (Folkman \& Lazarus, 1980), such as meditation (Cardoso, de Souza, \& Camano, 2009). Lastly, in addition to the more "novel" categories highlighted by McCleese and colleagues, we also examine non-work activities, as it includes a career-specific coping behavior (mentoring), in addition to more general activities such as exercise and leisure activities (McCleese, et al., 2007). Following this logic and rationale, we make the following prediction:

Hypothesis 3: Plateau coping will be negatively related to stress.

\section{Method}

\subsection{Participants}

Participants included graduate students from selected programs in two universities in the South-East United States. Participation was solicited from graduate students in Business (MBA), Public Administration (MPA), Psychology (MS, PhD), and Social Work (MSW) in one university and Human Resource Education (MS, PhD) in the other. The targeted graduate programs tend to have a preponderance of their students working full-time. The survey focused on their experiences as employees, not necessarily as students. The targeted programs reflect a variety of disciplines/fields which may mirror the occupational diversity of employees in any organization. Voluntary participation was solicited via an email containing a link to the online survey, which was distributed to all graduate students enrolled in the various programs by their respective program coordinators/chairs. To increase the response rate, several reminders were sent to respondents.

A total of one hundred and twenty-three completed surveys were considered usable for this study. The highest proportion of respondents were young adults, $21 \%$ of them falling between $25-29$ years, and about half (50\%) between 25-39 years. The majority of respondents were female (69\%), married (48\%), had worked full-time for fifteen or more years (40\%), and occupied junior or entry-level positions (52\%). The majority also reported having worked in their current position for less than five years (52\%), and 52\% worked for large organizations or ones with more than 250 employees.

\subsection{Measures}

Hierarchical plateau was assessed using Milliman's (1992) 6-item scale designed to measure the likelihood of future vertical advancement (e.g., "I am unlikely to obtain a higher job title in my organization"). The instrument returned a high internal consistency $(\alpha .=.94)$. The measure was anchored on a 5-point Likert-type scale ranging from 1 (strongly disagree) to 5 (strongly agree) such that higher scores indicated greater perceptions of plateauing. Those with scale averages of 4 or above on the hierarchical plateau measure were considered to be hierarchically plateaued, and were coded as thus. Fifty-four percent of the respondents were hierarchically plateaued.

Job content plateau was measured using Milliman's (1992) 6-item scale designed to measure employees perceptions of the likelihood of future challenges and responsibilities in their jobs (e.g., "I will not be challenged in my current job"). The instrument had a high internal consistency $(\alpha .=.91)$. The measure was anchored on a 5-point Likert-type scale ranging from 1 (strongly disagree) to 5 (strongly agree) such that higher scores indicated greater perceptions of plateauing. Those with scale averages of 4 or above on the hierarchical plateau measure were considered to be job-content plateaued, and were coded as thus. Thirty-seven percent of the respondents were job-content plateaued.

Double Plateau was considered to be those who had scale averages of 4 or above on both the hierarchical plateau and job content plateau. Thirty-one percent of the respondents were double plateaued.

Stress was measured using Cohen, Kamarck, and Mermelstein's (1983) 4-item Perceived Stress Scale, with modifications in the instructions to capture stress associated with plateaus. Respondents were asked to "keep their career situation in mind" while indicating how often they felt a certain way (e.g., "In the last month, how often have 
you felt that you were unable to control the situation", $\alpha .=.69)$. Items were measured on a 4-point Likert-type scale ranging from 1 (never) to 4 (very often) such that a higher score indicated greater stress.

Organization Citizenship Behaviors $(O C B 1 \& O C B O)$ were assessed using the 14-item scale developed by William and Anderson (1991). Seven of these items assessed OCBO (e.g., "I take action to protect the organization from potential problems", $\alpha .=.71$ ) while the remaining seven assessed OCBI (e.g., "I help others who have been absent", $\alpha$. $=.76)$. Respondents indicated their level of agreement with each statement on a 5-point Likert-type scale ranging from 1 (strongly disagree) to 5 (strongly agree), with higher scores representing higher incidence of OCBs.

Coping Behaviors were assessed with a scale developed by the researchers based on the work of McCleese et al., (2007) and Hurst and Kungu (2011). McCleese et al.'s (2007) study on career plateaus invited respondents to report in an open-ended question the strategies they employed to cope with both hierarchical and job content plateaus. A content analysis of those responses revealed seven categories of coping (discuss problem, job withdrawal, job involvement, non-work activities, mental coping, nothing, and side work). In the present study, questions were developed to capture each dimension of coping. The questions were subjected to a face and content validity examination by experts in Management and Organization Behavior fields. The experts reviewed the questions for readability and clarity, and they rated how important each coping strategy was for the dimension of coping under which it was listed. A total of 25 questions were retained in the final scale to assess the seven coping strategies. Items within each dimension were dropped if such an action improved the reliability estimate. Whereas the generally accepted lower limit for Cronbach alpha is .70, in exploratory research it may drop to .60 (Hair, Anderson, Tatham, \& Black, 1998). Because of the exploratory nature of the research questions and initial use of the scale, dimensions which had an alpha of approximately .60 were also used for analysis.

Non-work activities coping strategies was measured using a 6-item scale which captured activities pursued outside of the workplace (e.g. "Engaged in physical exercise", $\alpha .=.63$ ). Job involvement was assessed using a 4-item scale which covered coping strategies involving attempts to get more involved at work (e.g. "Increased my job knowledge", $\alpha .=.59$ ). Job withdrawal was measured using two items assessing strategies involving withdrawing from work (e.g. "Avoided taking on more responsibility at work", $\alpha .=.54)$. Respondents rated how often they used listed strategies on a five-point Likert-type scale ranging from 1 (never) to 5 (almost always).

Respondents were also asked to provide demographic information including age, gender, marital status, years of full-time work experience, length in current position, size of the organization and job type.

\section{Results}

The means, standard deviations, reliabilities and correlations among variables in this study are shown in Table 2 . Hypothesis 1, which suggested that plateaus will be positively related to stress, was assessed by correlating both hierarchical plateaus and job content plateaus with stress. Hypothesis 1 was only partially supported, as the correlation between stress and hierarchical plateaus was significant $(r=.35, p<.05)$ while the correlation with job content plateau was not (see Table 2).

To test Hypothesis 2, which posited that plateaus will be negatively related to organizational citizenship behaviors, both OCBI and OCBO scores were correlated with job content and hierarchical plateau scores. Only one relationship, the correlation between job content plateau and OCBI, was significant $(r=-.22, p<.05)$, indicating that employees with high job content plateau perceptions tend to report lower engagement in OCBI. Therefore, Hypothesis 2 received only partial support.

Hypothesis 3 suggested that plateau coping will be negatively related to stress. To test this, the three coping strategies (non-work activities, job involvement and job withdrawal) were correlated with the stress scores. Non-work activities as a coping strategy was negatively related to stress $(r=-.33, p<.01)$, suggesting that higher reports of non-work activities are associated with reduced stress. Job involvement had a significant negative relationship with stress $(r$ $=-.33, p<.01)$, while the relationship between job withdrawal and stress was not significant $(r=.04)$. Taken together, these findings provide partial support for Hypothesis 3.

To answer Research Question 1, which asked whether plateaued and non-plateaued employees differed in their use of coping strategies, independent $\mathrm{T}$ tests were undertaken. Data was coded to create categories of non-plateaued, hierarchically plateaued, job content plateaued and double pleateaued employees. Comparisons were made between each of the three categories of plateaued employees (hierarchical, job content and double) and non-plateaued employees to determine whether they differed in their use of the three coping strategies: non-work activities, job involvement, and job withdrawal (See Table 2). The rationale here was to assess if there were differences in use of coping strategies between respondents who reported experiencing some type of plateau and those who did not report 
any plateau at all. Also, differences in coping strategies use between three categories of plateaued employees were explored to determine whether respondents reporting different plateaus reported different coping approaches (See Table 3). Lastly, comparisons were made between plateaued and non-plateaued employees within each plateau category (i.e. hierarchical plateaued and hierarchical non-plateaued; job content plateaued and job content non-plateaued employees) to assess whether they differed in their use of coping strategies (See Table 4). The aim was to assess whether there were plateau-specific differences in the use of coping strategies between plateaued and non-plateaued in each plateau category.

Whereas differences were observed in the means between the various groups in their use of coping strategies, only two of these were statistically significant. There was a significant difference between non-plateaued and double-plateaued employees in their use of non-work coping strategies. Non-plateaued employees reporting higher usage of non-work coping strategies $(\mathrm{M}=2.51, \mathrm{SD}=.46)$ compared to double plateaued employees $(\mathrm{M}=2.31, \mathrm{SD}=.46), t(86)=2.10, p$ $<.05$ (See Table 3).

There was also a significant difference between the hierarchically plateaued and hierarchically non-plateaued (those who are not experiencing a hierarchical plateau but could be experiencing a job content plateau or no plateau at all) in their use of non-work coping strategies. Hierachically non-plateaued respondents had a higher mean for non-work coping strategies $(\mathrm{M}=2.50, \mathrm{SD}=.47)$ as compared to hierarchically plateaued respondents $(\mathrm{M}=2.32, \mathrm{SD}=.47), t(121)$ $=2.06, p<.05$ (See Table 4).

\section{Discussion}

Results of this study reveal four important findings. First, hierarchical plateaus, but not job content, are associated with higher stress. Second, this study expands the outcomes associated with plateauing by revealing a negative relationship between job content plateaus and individually-focused OCBs. Third, differences in coping were noted, with non-plateaued employees reporting more use of non-work coping strategies than double plateaued employees and hierarchically non-plateaued employees reporting higher use of non-work coping strategies than hierarchically plateaued employees. Lastly, two plateau coping strategies (job involvement and non-work coping) are associated with lower stress.

In contrast to McCleese et al. (2007), the results of the present study found that hierarchical plateaus were positively related to stress but job content plateaus were not. However, our findings are consistent with the results of Allen et al.'s (1998) study, which also found that hierarchical plateaus may be more stressful than job content. One possible explanation for McCleese et al.'s conflicting findings is that because their sample focused solely on plateaued employees, they compared plateaued employees' stress to normative data on stress experienced by working adults. While their research indicated that job content plateaued employees' stress was higher than that experienced in the general population, it might not be high enough to warrant concern for employers. Another possibility is that job content plateaued employees are finding other ways to cope and reduce stress beyond the strategies examined here. Therefore, future research should also explore coping strategies such as discussing the problem and mental coping (McCleese et al., 2007) in relation to job content plateaus. Longitudinal work is also warranted to address the causal relationships among plateaus, stress, and coping.

In terms of OCBs, the finding that job content plateaus were negatively related to individually-focused forms of OCBs is consistent with research revealing a negative relationship between plateauing and job performance (Allen, et al., 1998; Ettington, 1998; Lemire et al., 1999). Interestingly, hierarchical plateaus were not significantly related to OCBs. While speculative, it may be that individuals who are bored with and unchallenged by their jobs (i.e., job content plateaued) intentionally withhold helping behaviors aimed at assisting their coworkers as a way to retaliate for their boredom. Alternatively, it is possible that individual-focused forms of OCB are a cause, rather than a consequence, of job content plateaus. In other words, it could be that by assisting coworkers, some employees are able to avoid becoming job content plateaued. Perhaps doing so adds to the level of challenge or responsibility experienced in their careers. The findings of the present study add to the literature by identifying a link between OCBs and job content plateaus. However, because we are unable to draw conclusions about causality, future models of plateauing should incorporate OCBs to further explore their role in the experiences of job content plateaued employees.

In terms of coping, non-plateaued employees reported more use of non-work coping strategies than double-plateaued employees. Additionally, hierarchically non-plateaued employees reported higher usage of non-work coping strategies than hierarchically plateaued employees. These findings are important because, to date, the literature has only included a focus on how plateaued employees cope with their career stagnation. However, understanding the actions of non-plateaued employees offers a more complete perspective of stress and coping in relation to career advancement, as this group of employees has been successfully able to avoid a plateau. In this case, non-plateaued employees endorsed 
activities such as engaging in physical exercise or leisure activities, spending time with friends and family, relaxing, pursuing stress management education, and mentoring others. Overall, these activities reflect very general forms of coping aimed at helping employees decompress away from their work lives. On the other hand, mentoring others might help employees with their career development in a more proactive way. In McCleese and colleagues' (2007) study, employees who reported use of this coping strategy mentioned mentoring relationships undertaken informally and outside of the workplace, which may explain why it is not considered a "job-involvement" form of coping. However, the leadership skills gained from such a relationship could still transfer back to the workplace, potentially reducing the likelihood of hierarchical plateauing. Likewise, mentoring a young adult in one's free time could add to an individual's perceptions of challenge and responsibility in their daily interactions, reducing the likelihood of experiencing job content plateaus. These results, taken together with the finding that non-work activities were associated with less stress suggests the need for further studies to investigate the reasons behind this dynamic and also investigate its potential as an effective coping strategy.

The finding that job involvement and non-work coping strategies were associated with lower stress is consistent with decades of research on the role of coping in reducing stress (e.g., Folkman \& Lazarus, 1980; Judge, Thoresen, Pucik, \& Welbourne, 1999; Lazarus \& Folkman, 1984; Pearlin \& Schooler, 1978). It is also consistent with Rotondo and Perrewe's (2000) finding that "positive activities" coping strategies were associated with more positive attitudes and higher perceived job performance than "negative denial" coping responses. We encourage future research to explore the full range of plateau coping strategies in relation to stress in order to assist researchers and practitioners in their efforts to recommend adaptive coping strategies.

\subsection{Implications for Practice and Research}

In terms of managerial implications, coping workshops (e.g., Rowe, 1999) addressing job involvement and non-work coping strategies could be developed to aid employees in understanding the options available both within and outside the work environment. This could assist in encouraging constructive forms of coping since Elsass and Ralston (1989) describe a number of negative coping strategies that could have serious consequences for organizations if frustrated employees select them. For example, the authors argue that plateaued employees might lower their performance or abuse alcohol or drugs if they see no other positive alternatives for dealing with their plateau. Increasing the awareness and availability of positive forms of coping may help prevent negative coping.

The primary research implication relates to the importance for future research on coping with plateaus to consider the experiences of not just those who are plateaued, but also non-plateaued employees. These employees have successfully avoided plateaus and their experiences may provide valuable insight into the full range of coping strategies available to employees. Therefore, researchers should continue to maintain distinctions between hierarchical, job content, and double plateaus, but also incorporate experiences of non-plateaued employees.

\subsection{Areas for Future Research}

In order to fully understand why hierarchical plateaus are associated with higher stress than job content plateaus, future research should identify the information plateaued employees use to appraise a plateau as stressful (Hurst \& Eby, 2010). In other words, for those who do find the experience stressful, are their appraisals based on their own personal career image, external pressures, concerns about future earning potential and external marketability, or other factors?

Some researchers have argued that plateaus are not always a negative experience for employees. For example, McCleese and Eby (2006) found that job content plateaued employees were less negatively impacted by plateauing when role ambiguity was low. Additional research is needed examining the boundary conditions of plateauing. There may be other characteristics of individuals' work or home environments that lessen the negative impact of plateauing. For example, individuals experiencing plateaus early in their careers might report higher stress than those who plateau later in their careers. Likewise, individuals caring for young children or aging parents might view a plateau in a positive light if it allows them the opportunity to focus more on family responsibilities.

Lastly, with the increasingly diverse workforce, it is important to examine any potential cultural differences in the variables examined in the present study. In particular, perceptions of plateaus and subsequent coping strategies may be very different depending on one's cultural background and expectations at work. Therefore, a comprehensive measure of plateau coping is needed and should be validated among culturally diverse samples of plateaued employees.

\subsection{Limitations and Conclusion}

Several limitations to the findings of this study are worth noting. First, the sample was comprised of individuals pursuing graduate education, which may raise concerns regarding the generalizability of findings. However, the fact that almost half had worked full-time for over 15 years makes their perspectives important. That said, future research 
should attempt to confirm findings of this study among a group of employees representing a wider range of occupations.

A second set of limitations involves the research design, which relied on cross sectional data and self-report measures. This type of design leads to concerns about common method bias and reverse causality. The contrasting relationships between stress and OCBs for hierarchical and job content plateaued employees provide some evidence that the observed relationships were not simply a function of common method bias, but additional research is warranted before drawing any firm conclusions about causality.

Thirdly, measures for coping strategies reported less than ideal reliability estimates and should be interpreted with caution. While this study is the first undertaking to develop theoretically-driven items derived from the literature on employees own accounts of coping, future research should focus on developing more robust measures of the coping strategies among a large, diverse sample of plateaued employees.

Despite these limitations, the findings of this study address important gaps in the literature by expanding the nomological network of variables considered in relation to experiencing a plateau and by considering non-plateaued employees' experiences with respect to coping. This is important for both researchers and managers who are interested in assisting employees in dealing with their unique career experiences and understanding the role coping may play in either coping with or preventing plateauing.

\section{References}

Allen, T. D., Russell, J. E. A., Poteet, M. L., \& Dobbins, G. H. (1999). Learning and Development Factors Related to Perceptions of Job Content and Hierarchical Plateauing. Journal of Organizational Behavior. 20. 1113-1137. http://dx.doi.org/10.1002/(SICI)1099-1379(199912)20:7<1113::AID-JOB944>3.0.CO;2-7

Allen, T. D., Poteet, M. L., \& Russell, J. E. A. (1998). Attitudes of Managers Who Are More or Less Career Plateaued. Career Development Quarterly. 47. 159-172. http://dx.doi.org/10.1002/j.2161-0045.1998.tb00549.x

Arthur, M. B., \& Rousseau, D. M. (1996). The boundaryless career: A new employment principle for a new organizational era (pp. 237-255). New York: Oxford University Press.

Blau, P. M. (1964), Exchange and Power in Social Life. New York: John Wiley.

Bureau of Labor Statistics (2011). http://www.bls.gov/ Retrieved from web 6/19/2012.

Cardoso, R., de Souza, E., \& Camano, L. (2009). Meditation in health. In A. M. Rossi, J. C. Quick, \& P. L. Perrewe (Eds.). Stress and Quality of Working Life (pp. 143-166). Charlotte, NC: Information Age Publishing.

Chao, G. T. (1990). Exploration of the Conceptualization and Measurement of Career Plateau: A Comparative Analysis. Journal of Management. 16. 181-193. http://dx.doi.org/10.1177/014920639001600113

Chay, Y. W., Aryee, S., \& Chew, I. (1995). Career Plateauing: Reactions and Moderators among Managerial and Professional Employees. The International Journal of Human Resource Management. 6. 61-78. http://dx.doi.org/10.1080/09585199500000003

Choy, M. R. \& Savery, L. K. (1998). Employee Plateauing: Some Workplace Attitudes. Journal of Management Development. 17. 392-401. http://dx.doi.org/10.1108/02621719810210983

Cohen, S., Kamarck, T., \& Mermelstein, R. (1983). A Global Measure of Perceived Stress. Journal of Health and Social Behavior. 24. 386-396. http://dx.doi.org/10.2307/2136404

de Carvalho Cunha, K. (2009). Management of quality of life at work in healthcare organizations. In A. M. Rossi, J. C. Quick, \& P. L. Perrewe (Eds.). Stress and Quality of Working Life (pp. 205-234). Charlotte, NC: Information Age Publishing.

Ettington, D. R. (1998). Successful Career Plateauing. Journal of Vocational Behavior. 52. 72-88. http://dx.doi.org/10.1006/jvbe.1997.1584

Ference, T. P., Stoner, J. A., \& Warren, E. K. (1977). Managing the Career Plateau. Academy of Management Review. 2. 602-612. http://dx.doi.org/10.5465/AMR.1977.4406740

Folkman, S., \& Lazarus, R. (1980). An Analysis of Coping in a Middle-Aged Community Sample. Journal of Health \& Social Behavior. 21. 219-239. http://dx.doi.org/10.2307/2136617

Heilmann, S. G., Holt, D. T., \& Rilovick, C. Y. (2008). Effects of Career Plateauing on Turnover: A Test of a Model. Journal of Leadership and Organizational Studies. 15. 59-68. http://dx.doi.org/10.1177/1548051808317999 
Hurst, C. S., \& Eby, L. T. (2010). Plateaus and Appraisal: Characteristics and Experiences of Plateaued Employees. Journal of Knowledge \& Human Resource Management. 2. 10-19. http://www.intellectbase.org/e_publications.php

Hurst, C. S., \& Kungu, K. (2011). Coping Effectiveness: Differential Predictions for Plateaued Employees. Journal of Knowledge \& Human Resource Management. 3. 38-46. http://www.intellectbase.org/e_publications.php

Judge, T. A., Thoresen, C. J., Pucik, V., \& Welbourne, T. M. (1999). Managerial Coping with Organizational Change: A Dispositional Perspective. Journal of Applied Psychology. 84. 107-122. http://dx.doi.org/10.1037/0021-9010.84.1.107

Klehe, U., Zikic, J., Van Vianen, A. E. M., \& De Pater, I. E. (2011). Career Adaptability, Turnover, and Loyalty During Organizational Downsizing. Journal of Vocational Behavior. 79. 217-229. http://dx.doi.org/10.1016/j.jvb.2011.01.004

Lazarus, R. \& Folkman S. (1984). Stress, appraisal, and coping. New York: Springer Publishing Company.

Lemire, L., Sada, T., \& Gagnon, Y. C. (1999). Managing Career Plateauing in the Quebec Public Sector. Public Personnel Management. 28. 375-391. http://www.ipma-hr.org/publications/

Lee P. C. B. (2003). Going Beyond Career Plateau. Journal of Management Development. 22. 538-551. http://dx.doi.org/10.1108/02621710310478503

McCleese, C. S., \& Eby, L. T. (2006). Reactions to Job Content Plateaus: Examining Role Ambiguity and Hierarchical Plateaus as Moderators. Career Development Quarterly. 55(1). 64-76. http://dx.doi.org/10.1002/j.2161-0045.2006.tb00005.x

McCleese, C. S., Eby, L. T., Scharlau, E. A., \& Hoffman, B. H. (2007). Hierarchical, Job Content, and Double Plateaus: A Mixed-Method Study of Stress, Depression, and Coping Responses. Journal of Vocational Behavior. 71. 282-299. http://dx.doi.org/10.1016/j.jvb.2007.05.001

Milliman, J. F. (1992). Causes, consequences, and moderating factors of career plateauing. Unpublished doctoral dissertation. University of Southern California.Near, J. P. (1985). A Discriminant Analysis of Plateaued Versus Nonplateaued Managers. Journal of Vocational Behavior. $26 . \quad$ 177-188. http://dx.doi.org/10.1016/0001-8791(85)90017-X

Pearlin, L., \& Schooler, C. (1978). The Structure of Coping. Journal of Health and Social Behavior. 19. 2-21. http://dx.doi.org/10.2307/2136319

Podsakoff, P. M., MacKenzie, S. B., Paine, J. B., \& Bachrach, D. G. (2000). Organizational Citizenship Behaviors: A Critical Review of the Theoretical and Empirical Literature and Suggestions for Future Research. Journal of Management. 26. 513-563. http://dx.doi.org/10.1177/014920630002600307

Rotondo, D. M., \& Perrewe, P. L. (2000). Coping with a Career Plateau: An Empirical Examination of What Works and What Doesn't. Journal of Applied Social Psychology. 30. 2622-2646. http://dx.doi.org/10.1111/j.1559-1816.2000.tb02453.x

Rowe, M. M. (1999). Teaching Health-Care Providers Coping: Results of a Two-Year Study. Journal of Behavioral Medicine. 22. 511-527. http://dx.doi.org/10.1023/A:1018661508593

Tremblay, M., \& Roger, A. (1993). Individual, Familial, and Organizational Determinants of Career Plateau: An Empirical Study of the Determinants of Objective and Subjective Career Plateau in a Population of Canadian Managers. Group \& Organization Management. 18. 411-435. http://dx.doi.org/10.1177/1059601193184003

Tremblay, M., Roger, A., \& Toulouse, J. (1995). Career Plateau and Work Attitudes: An Empirical Study of Man. Human Relations. 48. 221-236. http://dx.doi.org/10.1177/001872679504800301 
Table 1. Means, Standard Deviations, Reliabilities and Correlations among Study Variables

\begin{tabular}{llllllllll}
\hline & Mean (SD) & JCP & HP & OCBI & OCBO & ST & NW & JI & JW \\
\hline & & & & & & & & & \\
\hline Job Content Plateau (JCP) & $2.72(.90)$ & .91 & $.57^{* *}$ & $-.22^{*}$ & -.10 & .17 & -.01 & -.17 & .10 \\
Hierarchical Plateau (HP) & $3.36(1.10)$ & & .94 & -.08 & -.16 & $.35^{* *}$ & -.15 & -.16 & .05 \\
OCBI & $4.06(.47)$ & & & .76 & .13 & -.09 & -.01 & .06 & -.08 \\
OCBO & $4.25(.48)$ & & & & .71 & $-.21^{*}$ & .10 & .08 & -.23 \\
Stress (ST) & $2.57(.56)$ & & & & & .69 & $-.33^{* *}$ & $-.22^{*}$ & .04 \\
Non-Work Activities (NW) & $2.40(.48)$ & & & & & & .63 & $.21^{*}$ & .13 \\
Job Involvement (JI) & $2.59(.54)$ & & & & & & & .59 & .12 \\
Job Withdrawal (JW) & $1.45(.53)$ & & & & & & & & .54 \\
\hline
\end{tabular}

Notes. ${ }^{* *} . r$ is significant at $p<.01 ; * . p<.05$. Reliabilities (Cronbach's alpha coefficients) are on the main diagonal

Table 2. Non-Work, Job Involvement and Job Withdrawal Coping Strategies Means for Plateaued and Non-Plateaued Respondents

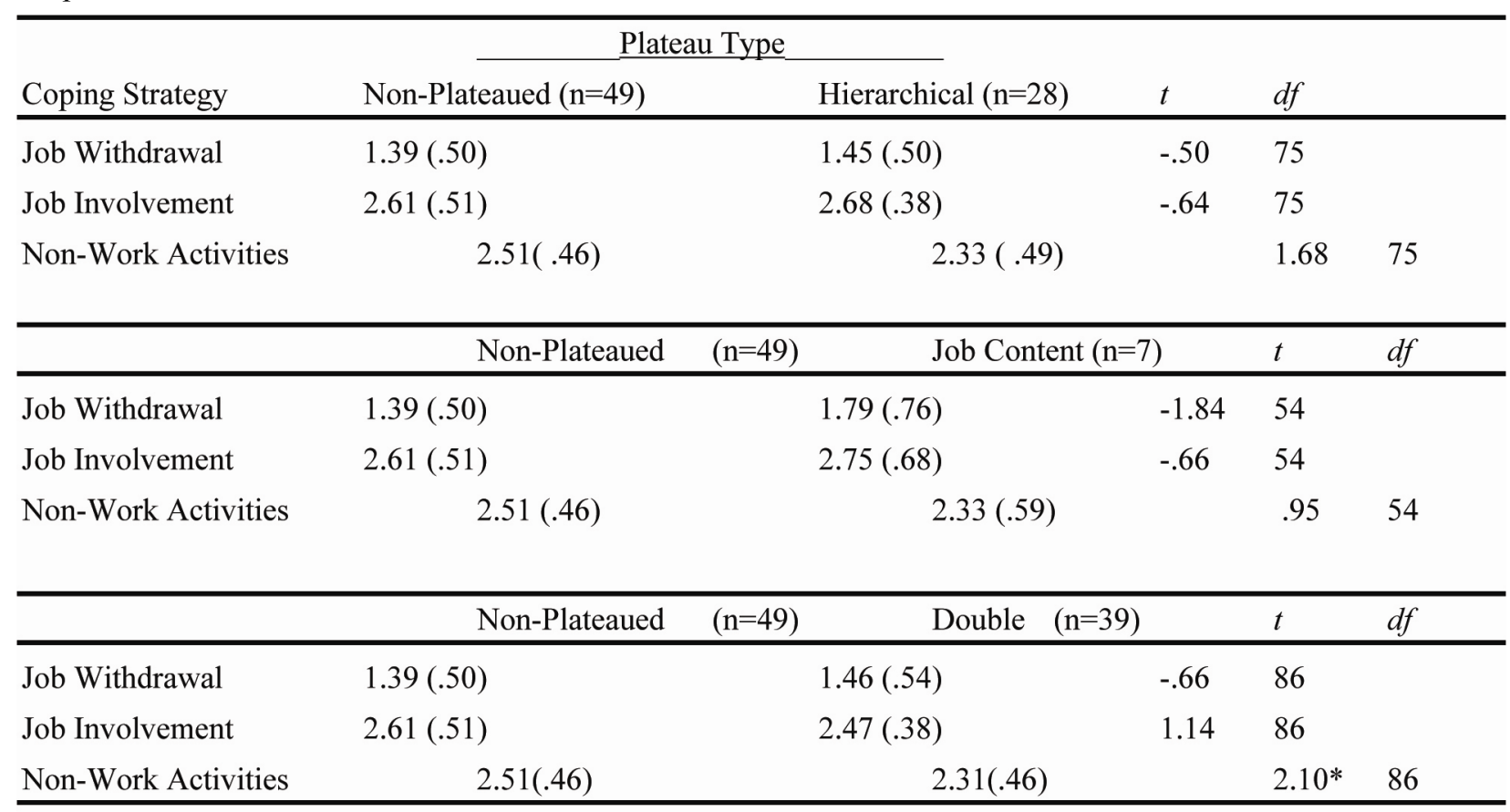

Notes. ${ }^{*} . r$ is significant at $p<.05$. Standard Deviations in parentheses 
Table 3. Non-Work, Job Involvement and Job Withdrawal Coping Strategies Means for Hierarchical, Job Content and Double Plateaued Respondents

\begin{tabular}{|c|c|c|c|c|c|}
\hline \multicolumn{6}{|c|}{ Plateau Type } \\
\hline Coping Strategy & Hierarchical $(n=28)$ & Job Content $(\mathrm{n}=7)$ & $t$ & $d f$ & \\
\hline Job Withdrawal & $1.45(.50)$ & $1.79(.76)$ & -1.45 & 33 & \\
\hline Job Involvement & $2.68(.38)$ & $2.75(.68)$ & -.37 & 33 & \\
\hline Non-Work Activities & $2.33(.49)$ & $2.33(.59)$ & -.03 & 33 & \\
\hline & Hierarchical $(n=28)$ & Double $(n=39)$ & & $t$ & $d f$ \\
\hline Job Withdrawal & $1.45(.50)$ & $1.46(.54)$ & -1.17 & 65 & \\
\hline Job Involvement & $2.68(.38)$ & $2.47(.63)$ & 1.57 & 65 & \\
\hline Non-Work Activities & $2.33(.49)$ & $2.31(.46)$ & .17 & 65 & \\
\hline & Job-Content $(n=7)$ & Double $(n=39)$ & & $t$ & $d f$ \\
\hline Job Withdrawal & $1.79(.76)$ & $1.46(.54)$ & 1.37 & 44 & \\
\hline Job Involvement & $2.75(.51)$ & $2.47(.63)$ & 1.08 & 44 & \\
\hline Non-Work Activities & $2.33(.59)$ & $2.31(.46)$ & .13 & 44 & \\
\hline
\end{tabular}

Notes. ${ }^{*} . r$ is significant at $p<.05$. Standard Deviations in parentheses

Table 4. Non-Work, Job Involvement and Job Withdrawal Coping Strategies Means for Hierarchical, Hierarchical Non-Plateaued, Job Content and Job Content Non-Plateaued Respondents

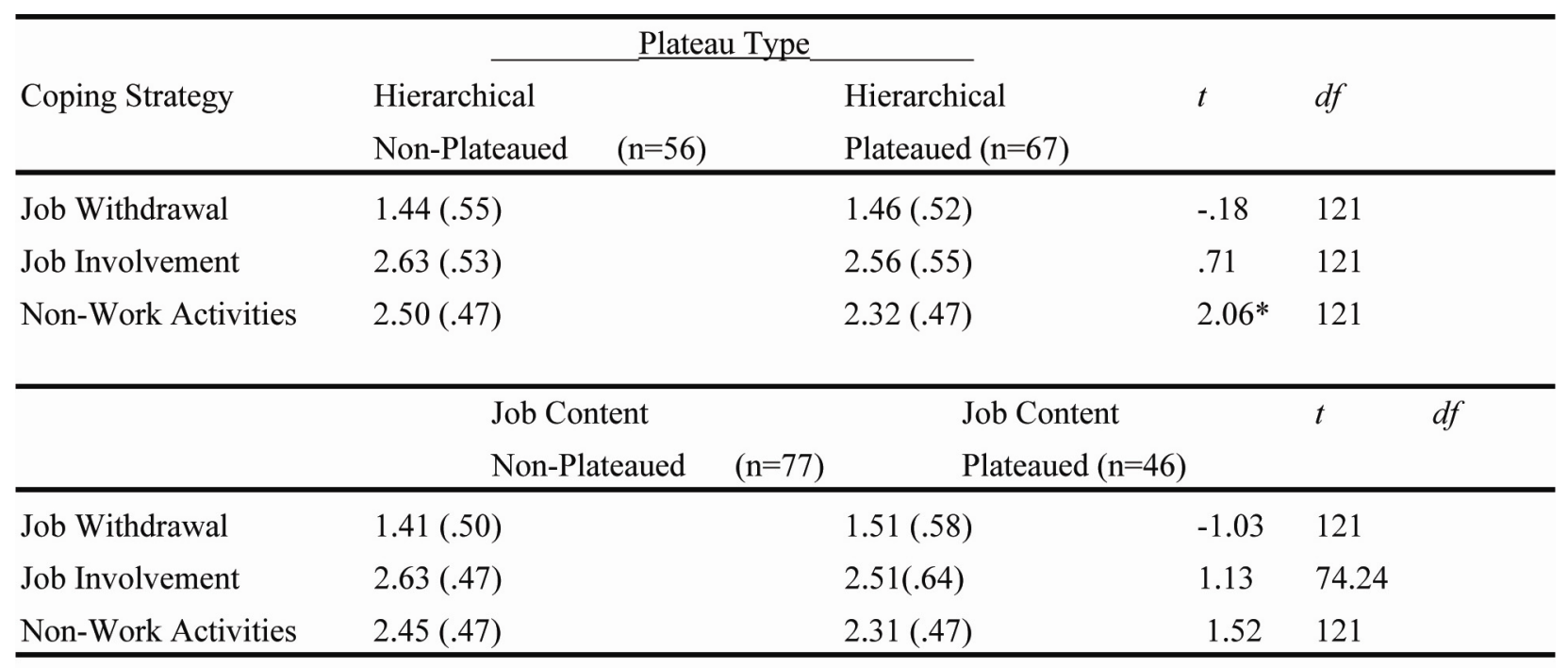

Notes. ${ }^{*} . r$ is significant at $p<.05$. Standard Deviations in parentheses 